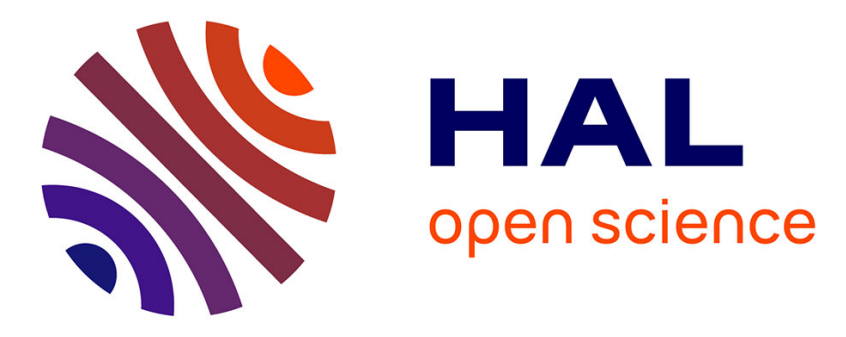

\title{
Wave and Tide Controls on Rip Current Activity and Drowning Incidents in Southwest France
}

Bruno Castelle, Tim Scott, Rob Brander, R Jak Mccarroll, Eric Tellier, Elias

de Korte, Léana Tackuy, Arthur Robinet, Bruno Simonnet, Louis-Rachid

Salmi

\section{To cite this version:}

Bruno Castelle, Tim Scott, Rob Brander, R Jak Mccarroll, Eric Tellier, et al.. Wave and Tide Controls on Rip Current Activity and Drowning Incidents in Southwest France. Journal of Coastal Research, 2020, 95, 10.2112/si95-150.1. hal-03044408

\section{HAL Id: hal-03044408 \\ https://hal.science/hal-03044408}

Submitted on 14 Dec 2020

HAL is a multi-disciplinary open access archive for the deposit and dissemination of scientific research documents, whether they are published or not. The documents may come from teaching and research institutions in France or abroad, or from public or private research centers.
L'archive ouverte pluridisciplinaire HAL, est destinée au dépôt et à la diffusion de documents scientifiques de niveau recherche, publiés ou non, émanant des établissements d'enseignement et de recherche français ou étrangers, des laboratoires publics ou privés. 


\title{
Wave and Tide Controls on Rip Current Activity and Drowning Incidents in Southwest France
}

\author{
Bruno Castelle ${ }^{\dagger *}$, Tim Scott ${ }^{\ddagger}$, Rob Brander ${ }^{\S}$, R. Jak McCarroll ${ }^{\ddagger}$ Eric Tellier ${ }^{\dagger \dagger}$, Elias de Korte ${ }^{\S \S}$, Léana Tackuy $^{\dagger}$, Ar- $^{\circ}$ \\ thur Robinet ${ }^{\dagger \dagger}$, Bruno Simonnet ${ }^{+*}$, and Louis-Rachid Salmi ${ }^{\dagger+{ }^{\dagger+}}$ \\ †CNRS, Université de \\ Bordeaux \\ UMR EPOC 6554, \\ OASU \\ Pessac, France \\ * Coastal Processes \\ Research Group \\ School of Biological and \\ Marine Sciences \\ University of Plymouth \\ Plymouth, UK \\ ${ }^{\S}$ School of Biological, \\ Earth and \\ Environmental \\ Sciences \\ University of New South \\ Wales \\ Sydney, Australia \\ ${ }^{\dagger}$ INSERM, Université \\ de Bordeaux \\ U1219 ISPED \\ Bordeaux population \\ health research \\ Bordeaux, France \\ www.cerf-jcr.org
}

"CHU de Bordeaux

Pôle Urgences adultes, SAMU-SMUR

Pôle de Santé Publique, SIM/UMES

Bordeaux, France

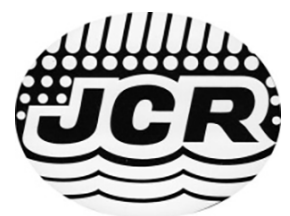

www.JCRonline.org

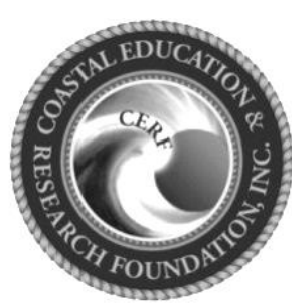

\author{
i†BRGM, French \\ Geological Survey
}
Pessac, France
MAR, Department of Faculty of Geos

Utrecht University

Utrecht, Netherlands

\begin{abstract}
Castelle, B.; Scott, T.; Brander, R.W.; McCarroll, R.J.; Tellier, E.; de Korte, E.; Tackuy, L.; Robinet, A.; Simonnet, B. and Salmi, L.-R., 2020. Wave and tide controls on rip current activity and drowning incidents in Southwest France. In: Malvárez, G. and Navas, F. (eds.), Global Coastal Issues of 2020. Journal of Coastal Research, Special Issue No. 95, pp. 769-774. Coconut Creek (Florida), ISSN 0749-0208.

The meso-macrotidal sandy surf beaches of southwest France are a popular destination visited by millions of tourists each summer, who potentially expose themselves to surf zone hazards and particularly to rip currents flowing through the inner-bar rip channels. 281 non-fatal and fatal drowning incidents, most of them caused by rip currents, recorded by lifeguards during the summer 2007, 2009 and 2015 were combined with measured and hindcast wave and tide data. Results show that drownings occur disproportionally near neap low tide, under shore-normal incident waves and average to above-average height and period, with drowning incidents tending to occur in clusters with particular days of mass incidents. An XBeach model is implemented on measured rip-channelled bathymetries to address the influence of offshore wave conditions and tidal elevation on rip flow dynamics and resulting hazard. Simulations show that rip flow increases with increasing wave height, increasing wave period and increasingly shore-normal incidence, which is consistent with the increased number of drowning incidents for such conditions. Although more incidents also tend to occur on warm sunny days with light winds, presumably driving more exposure to the rip current hazard, this highlights the dominance of the physical hazard on the life risk along this stretch of coast.
\end{abstract}

ADDITIONAL INDEX WORDS: Rip current, drowning incident, environmental controls, beach safety.

\section{INTRODUCTION}

It is well established that rip currents are the leading cause of both fatal and non-fatal drowning incidents on surf beaches worldwide. Rips are strong, narrow seaward flowing currents often originating close to the shoreline (Castelle et al., 2016a; Dalrymple et al., 2011; MacMahan et al., 2006) which, although potentially forming through a variety of driving mechanisms (Castelle et al., 2016a), are essentially driven by the action of breaking waves. One of the most common rip types flows through channels incised in nearshore sandbars (e.g., Houser et al., 2013, MacMahan et al., 2006). Channel rip activity, and resulting physical hazard, is

DOI: 10.2112/SI95-150.1 received 31 March 2019; accepted in revision 13 February 2020

*Corresponding author: bruno.castelle@u-bordeaux.fr

${ }^{\circ}$ Coastal Education and Research Foundation, Inc. 2020 primarily controlled by offshore wave conditions (e.g., Brander, 1999; Bruneau et al., 2011) and tide elevation (e.g., Austin et al., 2014). Surf zone morphology is also critical to rip activity, with deeper rip channels resulting in more intense rips (e.g., McCarroll et al., 2018, Moulton et al., 2017).

The number of drowning incidents, or the overall drowning risk at a given coast, not only depends on the physical hazard (primarily rip currents), but also on beachgoer exposure. Warm sunny days with low winds typically result in increased beach attendance and beachgoer exposure to hazards and, in turn, more life risk. Understanding the environmental controls on life risk related to rip currents along the coast typically requires accurate drowning incident records combined with detailed wave, tide and weather data at the time of the incidents (Scott et al., 2014).

The southwest Gironde-Landes coast of France hosts $230 \mathrm{~km}$ of meso-macrotidal sandy surf beaches (Figure 1a) that are visited by 


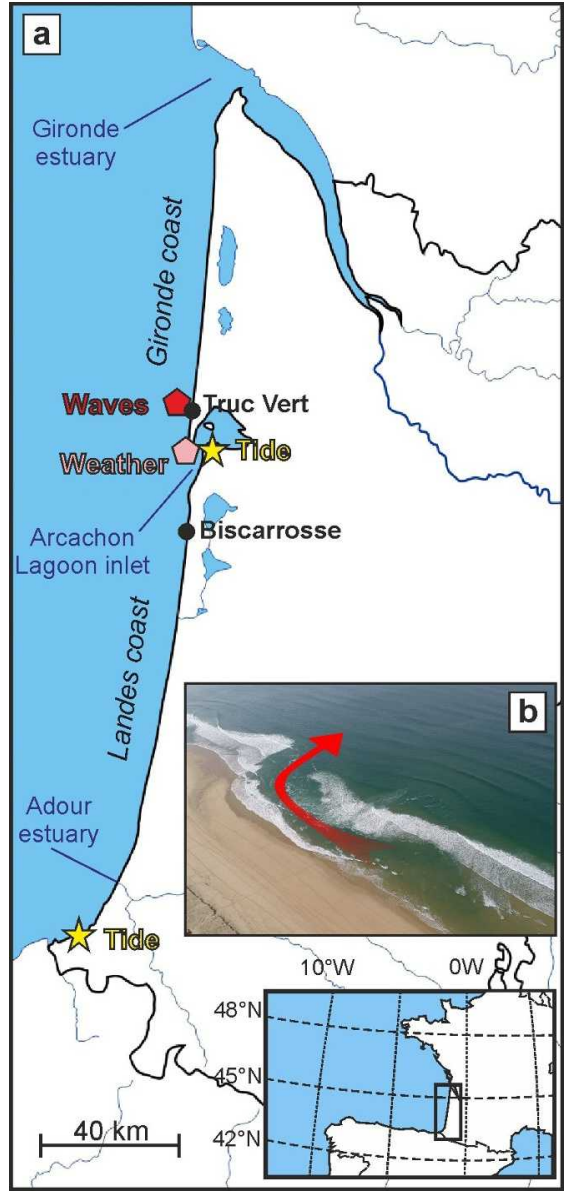

Figure 1. (a) Location map of the Gironde and Landes coasts in southwest France. Yellow stars indicate tide gauges, and the red and pink polygons show the location of the WavewatchIII model output grid point and weather station, respectively. (b) Aerial photograph of Truc Vert beach taken at low tide showing the presence of a classic rip current system along this coast (credit V. Marieu). millions of tourists each summer. Beaches are relatively straight (Figure $1 \mathrm{~b}$ ) and are exposed to high-energy ocean waves coming from the WNW direction (Castelle et al., 2017). Beaches are double-barred and rip-dominated (e.g., Bruneau et al., 2009) with rip current causing approximately $80 \%$ of drowning incidents (Castelle et al., 2018). Here we examine extensive environmental data to address the primary environmental controls on the full drowning risks along this stretch of coast, with the overreaching goal to improve future beach safety management and education of beach users in southwest France.

\section{Drowning Data}

\section{METHODS}

A comprehensive surf-zone injury (SZI) dataset, that comprised injury report forms filed for every incident, documented a total of 2523 SZIs over 186 sample days during the summers of 2007 , 2009 and 2015 (Castelle et al., 2018). Amongst all the data analyzed in Castelle et al. (2018), here we address 281 drowning incidents (Figure 2a,b) using: date and time of the incident; beach location; activity (e.g., wading, surfing, bodyboarding); cause of injury (e.g., rip current, shore-break waves); and injury type (e.g., drowning, spine injury). The drowning stage was also provided according to a 4-stage classification widely used in France, from the milder to the most severe: (1) exhaustion, but no sign of aspiration of water; (2) moderate respiratory impairment, anxiety; (3) altered consciousness, severe respiratory impairment or acute pulmonary edema, tachycardia or hypotension; and (4) coma, respiratory or cardiac arrest. $11.4 \%$ of the drowning incidents were severe (stage 3 and 4, Figure 2b), with most occurring outside of the supervised bathing zone (Figure 2d).

\section{Environmental Data}

Each incident was associated with: a significant wave height $H s$, mean and peak wave periods $T 02$ and $T p$, respectively, and wave angle $\theta$ from a 6-hourly wave hindcast (Boudière et al., 2013) at grid point $1.3232^{\circ} \mathrm{W}, 44.7374^{\circ} \mathrm{N}$ (Figure 1a) in approximately 30-m depth. A tidal component analysis of a 3-month time series of continuous, storm-free, tide gauge data (Figure 1a) was used to generate tide elevation time series.
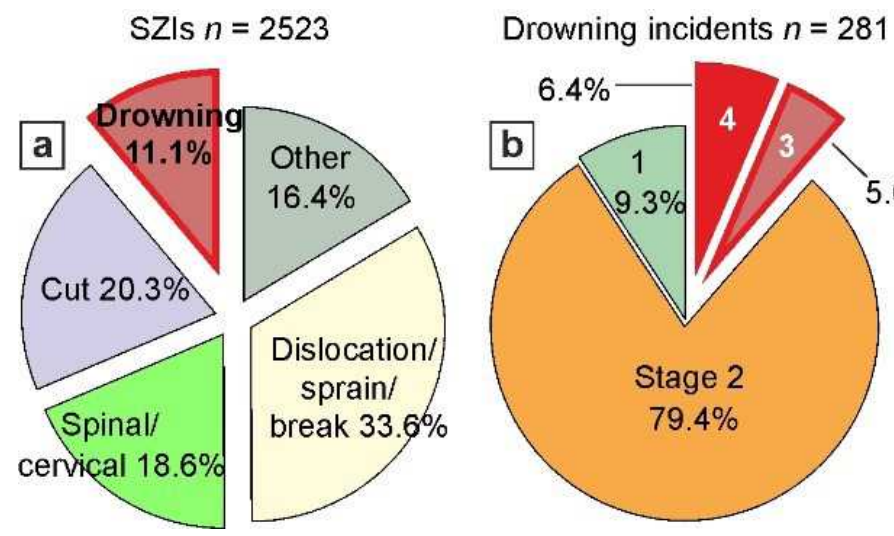

Milder drowning incidents
(stages 1 \& 2) $n=249$

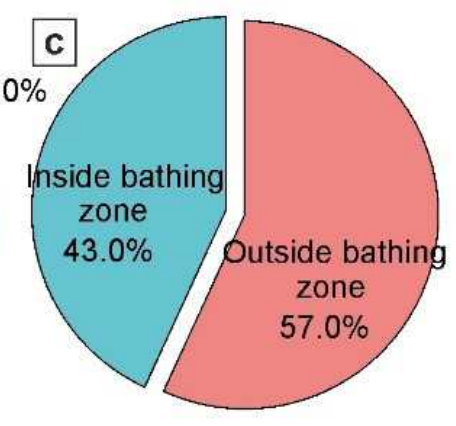

Severe drowning incidents (stages 3 \& 4) $n=32$

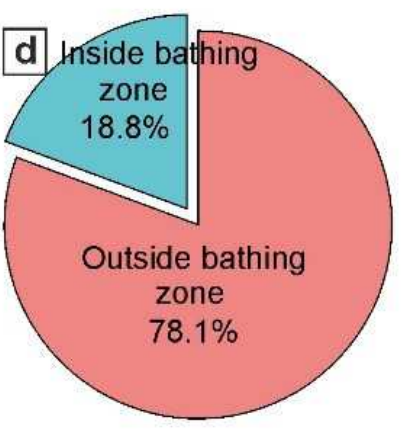

Figure 2. (a) Surf zone incidents related to injury type. (b) Drowning incidents related to drowning stage and location of the incident related to (c) milder drowning (stage $1 \& 2$ ) and (d) severe drowning (stage $3 \& 4$ ) with respect to supervised bathing zone. 

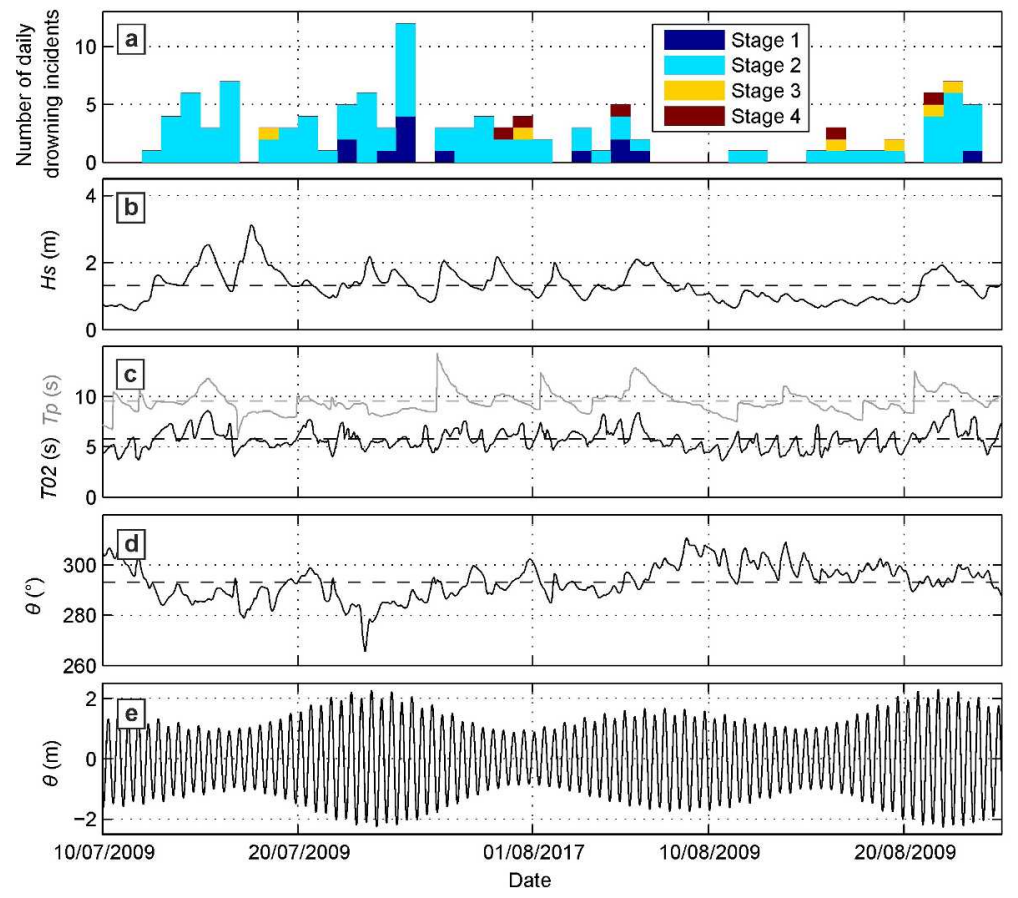

Figure 3. Time series during the 2009 summer of: (a) number of daily fatal and non-fatal drowning incidents; (b) significant wave height Hs; (c) peak (Tp, black line) and mean (T02, blue line) wave periods; (d) wave direction $\theta$; (e) water level $\eta$ with respect to mean sea level. In (b,c,d) the summer mean is indicated by the horizontal dashed line
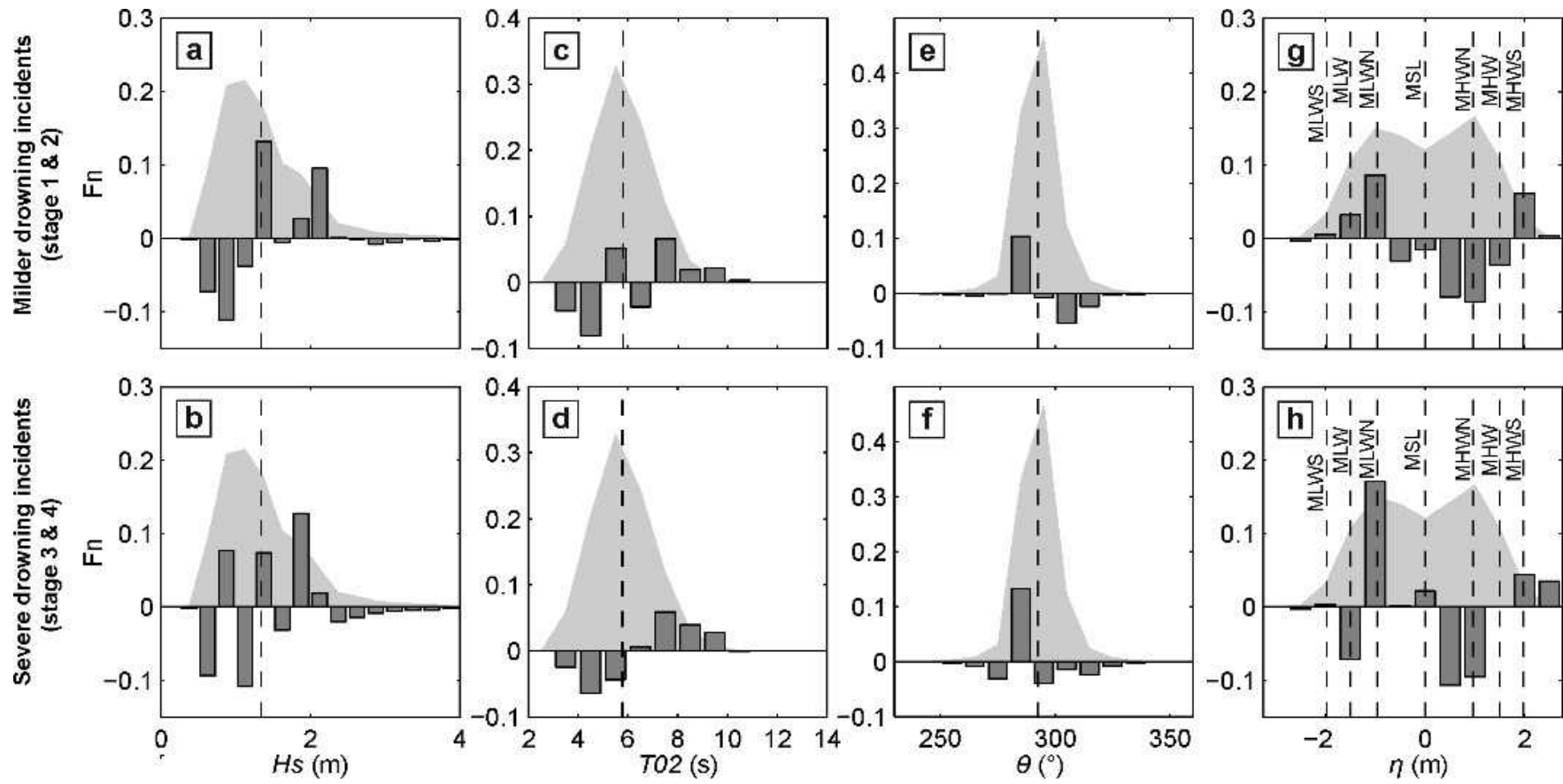

Figure 4. Environmental controls on drowning incidents: normalized frequency distributions Fn during the summers of 2007 , 2009 and 2015 (light grey region), referred to as 'average' background distribution, of (a,b) significant wave height Hs; (c,d) mean wave period T02; (e,f) wave direction $\theta$; ( , h) water level $\eta$. In all panels the dark grey bars show the difference between the surfing related and the 'average' background distributions and the vertical dashed lines in (a-f) show the background Top and bottom panels are for milder (stage 1 \& 2) and severe (stage 3 \& 4) drowning incidents, respectively. 


\section{Numerical Modelling}

An XBeach model (Roelvink et al., 2009) was implemented on a $10 \mathrm{~m} \times 10 \mathrm{~m}$ regular grid to address the influence of offshore wave conditions and tidal elevation on rip flow dynamics and resulting hazard. The model, which is depth-averaged and wave-group resolving, has been demonstrated to be suitable for this purpose even when default settings were used (Castelle et al., 2016b). The model was based on detailed topo-bathymetry collected during an intensive field experiment performed at Biscarrosse on June 13-17 2007 (Bruneau et al., 2009, 2011), which is broadly representative of the coastal morphology. For more detail on the model implementation at Biscarrosse the reader is referred to Castelle et al. (2016b, 2019).

\section{RESULTS}

Figure 3 shows time series of wave/tide conditions and daily drowning incidents during the 2009 summer. Drowning incidents tend to occur in clusters. Overall, there appears to be no single environmental factor controlling the occurrence of drowning incidents (also considering weather factors, not shown). Instead, it is possible that certain combinations of environmental controls are conducive to causing drowning incidents. To better understand these combinations promoting risky conditions, the approach of Scott et al. (2014) was utilized whereby the environmental conditions during which incidents occurred were compared with the 'average' background conditions of the summer seasons. The average frequency distribution of these parameters was compared with those computed from the environmental parameters associated with each recorded rip incident. Differences between the distributions therefore provides an indication of environmental conditions that may be driving drowning incidents (Scott et al., 2014).

Figure 4 shows that, for both milder and severe drowning incidents, larger waves (Figure 4a,b) with longer period (Figure $4 \mathrm{c}, \mathrm{d})$ and more shore-normal incidence $\left(\sim 280^{\circ}\right.$, Figure $\left.4 \mathrm{e}, \mathrm{f}\right)$ increase the likelihood of drownings. Near-neap-low tide levels and, to a lesser extent, extremely-high-tide levels are also overrepresented. Interestingly, these trends appear more pronounced for the severe drowning incidents (lower panels in Figure 4), although the reasonably small number of such incidents $(n=$ 32) prevents from drawing conclusions. Additional analysis (not shown) also indicates that more drowning incidents occur on warm, sunny days with light winds (Castelle et al., 2019), presumably as a result of increased beach attendance and increased beachgoer exposure to physical hazard.

Figure 5 shows time series of drowning incidents, wave and tide conditions of the four days when the largest number drowning incidents in the entire dataset were reported. These four days were associated with average or above average wave height and period (Figure 5i-1) and near shore-normal wave incidence (not shown), but not for any particular tide range or low tide timing within the day. However, drowning incidents clearly occurred preferably for lower tide levels, consistent with Figure $4 \mathrm{~g}$, h, with some milder drowning incidents occurring for extremely high water level occurring in the afternoon (Figure 5d), likely when beach attendance is maximized with beachgoers exposing themselves to high-tide swash rips (Castelle et al., 2019). Severe drowning incidents can also occur in clusters before or after the supervised hours (11AM-7PM) around low tide levels even during the night (Figure 5d). These rare mass drowning events

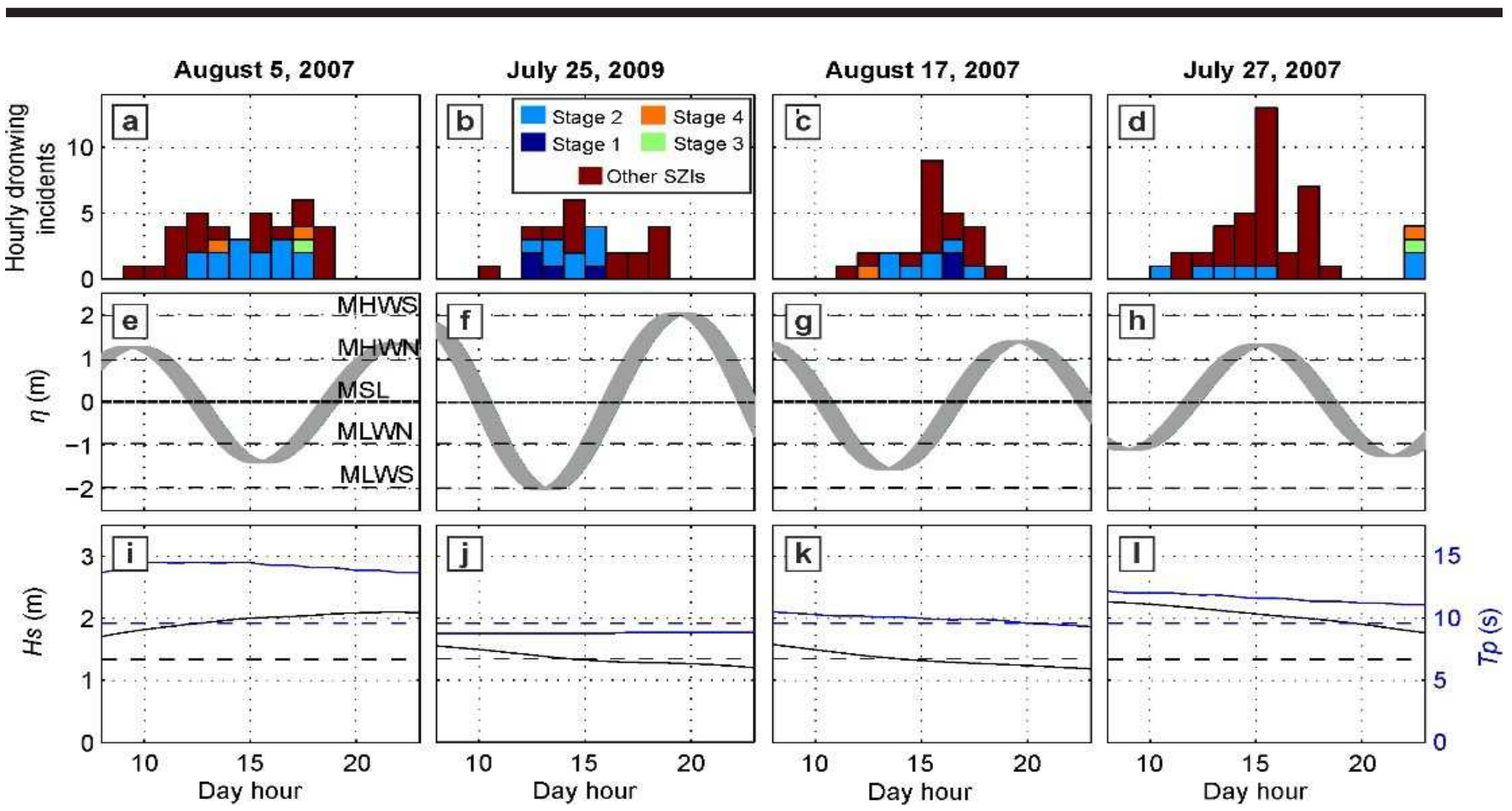

Figure 5. Time series on the four days with the largest number of drowning incidents in the entire dataset showing: (a-d) distribution drowning incidents with drowning stage colored; (e-h) tide elevation $\eta$; (i-l) significant wave height Hs and peak wave period Tp (c) with the horizontal dashed lines indicating the summer means. 

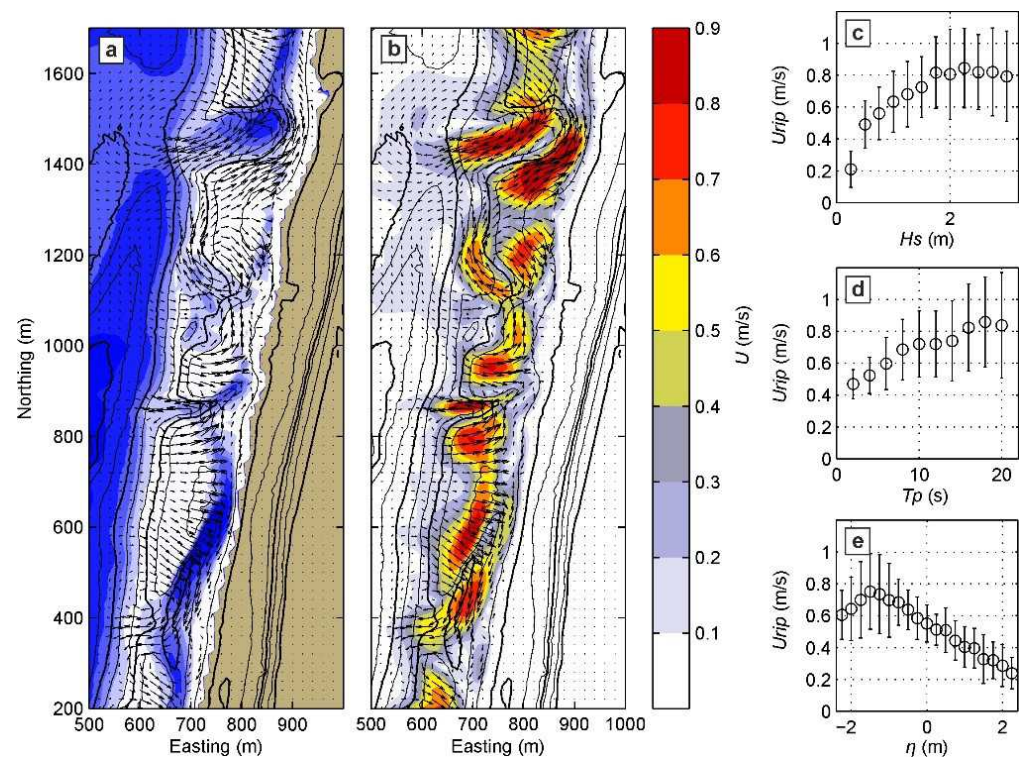

Figure 6. Wave-driven currents with (a) breaking wave patterns (white areas) and (b) flow intensity coloured at Biscarrosse beach for the reference simulation with $\mathrm{Hs}=1.5 \mathrm{~m}, \mathrm{Tp}=10 \mathrm{~s}, \theta=280^{\circ}, \eta=-1 \mathrm{~m}$. 20-min averaged rip flow velocity against (c) Hs, (d) Tp and (e) $\eta$.

are typically associated with risky behavior of an individual or group of individuals, for example when four drowning incidents (including one stage 3 and one stage 4) concomitantly occurred at Biscarrosse late at night on July 27, 2007.

To further explore the influence of wave and tide conditions on rip current activity in southwest France, we modelled nearshore hydrodynamics using morphology surveyed in mid-June 2007 at Biscarrosse, varying $H s$ from $0.25 \mathrm{~m}$ to $3 \mathrm{~m}$ (0.25-m interval), $T p$ from $4 \mathrm{~s}$ to $20 \mathrm{~s}$ ( 2 -s interval), $\theta$ from $280^{\circ}$ to $320^{\circ}\left(5^{\circ}\right.$ interval) and $\eta$ from $-2.2 \mathrm{~m}$ to $2.2 \mathrm{~m}(0.2-\mathrm{m}$ interval). The reference simulation was chosen for $H s=1.5 \mathrm{~m}, T p=10 \mathrm{~s}, \theta=280^{\circ}$ and $\eta=-1$ $\mathrm{m}$, which are the conditions corresponding to a disproportionate amount of drowning incidents observed in our dataset (Figure 4). The reference simulation (Figure 6a,b) shows intense rip currents through the four rip channels, although these rip currents contrast in terms of shape, width and intensity. Figure 6c-e shows that rip flow intensity averaged over the four rip current systems largely increases for increasing wave height (Figure 6c) and increasing wave period (Figure 6d) although rip flow speed tends to stabilize for $H s>1.8 \mathrm{~m}$ and $T p>15 \mathrm{~s}$. More intense rips also occur at lower tide levels, peaking around mean low water neap (Figure $6 \mathrm{e}$ ), in line with maximized incident data (Figure 4g,h). Rip flow speed is, however, largely variable alongshore (see the large error bars in Figure 6c-e) owing to the large variability in rip channel morphology. These results indicate that wave and tide conditions for which rip flow speed is maximized are approximately the same as those for which more drowning incidents are reported.

\section{CONCLUSIONS}

On the high-energy surf beaches of southwest France, summer drowning incidents occur disproportionally near neap low tide, under shore-normally incident waves and average to aboveaverage wave height and period. This is consistent with numerical modelling results that show flow intensity maximized for shorenormal incidence, around neap low tide levels and for increased wave height and period. This highlights the dominance of the physical hazard on the life risk along this stretch of coast and the potential for the development of drowning risk predictors along this coast.

\section{ACKNOWLEDGMENTS}

BC was funded by project SONO (ANR-17-CE01-0014) from the Agence Nationale de la Recherche (ANR). Truc Vert beach is labelled by the Service National d'Observation (SNO) Dynalit (https://www.dynalit.fr). Weather station and tide gauge data were provided by the Météo France Radome network and the SHOM, respectively.

\section{LITERATURE CITED}

Austin, M.J.; Masselink, G.; Scott, T.M., and Russell, P.E., 2014. Water level controls on macro-tidal rip currents. Continental Shelf Research, 75, 28-40.

Boudière, E.; Maisondieu, C.; Ardhuin, F.; Accensi, M.; PineauGuillou, L., and Lepesqueur, J., 2013. A suitable metocean hindcast database for the design of marine energy converters. International Journal of Marine Energy, 3-4, 40-52.

Brander, R.W., 1999. Field observations on the morphodynamic evolution of a low-energy rip current system. Marine Geology, 157, 199-217.

Bruneau, N.; Bonneton, P.; Castelle, B., and Pedreros, R., 2011. Modeling rip current circulations and vorticity in a highenergy meso-environment. Journal of Geophysical Research - Oceans, 116, C07026.

Bruneau, N.; Castelle, B.; Bonneton, P.; Pedreros, R.; Almar, R.; Bonneton, N.; Bretel, P.; Parisot, J.-P., and Sénéchal, N., 2009. Field observations of an evolving rip current on a mesomacrotidal well-developed inner bar and rip morphology. Continental Shelf Research, 29, 1650-1662. 
Castelle, B.; Scott, T.; Brander, R.W., and McCarroll, R.J., $2016 \mathrm{a}$. Rip current types, circulation and hazard. Earth-Science Reviews, 163, 1-21.

Castelle, B.; McCarroll, R.J.; Brander, R.W.; Scott, T., and Dubarbier, B., 2016b. Modelling the alongshore variability of optimum rip current escape strategies on a multiple ripchannelled beach. Natural Hazards, 81, 664-686.

Castelle, B.; Bujan, S.; Ferreira, S., and Dodet, G., 2017. Foredune morphological changes and beach recovery from the extreme 2013/2014 winter at a high-energy sandy coast. Marine Geology, 385, 41-55, 2017.

Castelle, B.; Scott, T.; Brander, R.W.; McCarroll, R.J.; Robinet, R.; Tellier, E.; de Korte, E.; Simonnet, B., and Salmi, L.R., 2019. Environmental controls on surf zone injuries on high-energy beaches. Natural Hazards and Earth System Sciences, 19, 2183-2205.

Dalrymple, R.A.; MacMahan, J.H.; Reniers, A.J.H.M., and Nelko, V., 2011. Rip currents. Annual Reviews in Fluid Mechanics, 43, 551-581.

Houser, C.; Arnott, R.; Ulzhofer, S., and Barrett, G., 2013. Nearshore circulation over transverse bar and rip morphology with oblique wave forcing. Earth Surface Processes and Landforms, 38, 1269-1279.

MacMahan, J.H.; Thornton E.B., and Reniers, A.J.H.M., 2006. Rip current review. Coastal Engineering, 53(2), 191-208.

McCarroll, R.J.; Brander, R.W.; Scott, T., and Castelle, B., 2018. Bathymetric controls on rotational surfzone currents. Journal of Geophysical Research - Earth Surface, 123, doi: 10.1029/2017JF004491.

Moulton, M.; Elgar, S.; Raubenheimer, B.; Warner, J.C., and Kumar, N., 2017. Rip currents and alongshore flows in single channels dredged in the surf zone. Journal of Geophysical Research - Oceans, 122, 3799-3816, doi: 10.1002/2016JC012222.

Roelvink, J.A.; Reniers, A.J.H.M.; van Dongeren, A.: de Vries, J. V.; McCall, R., and Lescinski, J., 2009. Modelling storm impacts on beaches, dunes and barrier islands. Coastal Engineering, 56, 1133-1152.

Scott, T.M.; Masselink, G.; Austin, M.J., and Russell, P., 2014. Controls on macrotidal rip current circulation and hazard. Geomorphology, 214, 198-215. 